\title{
Increased postpartum haemorrhage, the possible relation with serotonergic and other psychopharmacological drugs: a matched cohort study
}

Hanna M. Heller ${ }^{*}$, Anita C. J. Ravelli², Andrea H. L. Bruning ${ }^{3}$, Christianne J. M. de Groot ${ }^{4}$, Fedde Scheele ${ }^{5,6}$, Maria G. van Pampus ${ }^{7}$ and Adriaan Honig ${ }^{8,9}$

\begin{abstract}
Background: Postpartum haemorrhage is a major obstetric risk worldwide. Therefore risk factors need to be investigated to control for this serious complication. A recent systematic review and meta-analysis revealed that the use of both serotonergic and non-serotonergic antidepressants in pregnancy are associated with a higher risk of postpartum haemorrhage. However, use of antidepressants in pregnancy is often necessary because untreated depression in pregnancy is associated with adverse maternal and neonatal outcome, such as postpartum depression, preterm birth and dysmaturity. Therefore it is of utmost importance to unravel the possible association between postpartum haemorrhage and the use of serotonergic and other psychopharmacological medication during pregnancy.
\end{abstract}

Methods: We performed a matched cohort observational study consecutively including all pregnant women using serotonergic medication $(n=578)$ or other psychopharmacological medication $(n=50)$ visiting two teaching hospitals in Amsterdam between 2010 and 2014. The incidence of postpartum haemorrhage in women using serotonergic medication or other psychopharmacological medication was compared with the incidence of postpartum haemorrhage in 641,364 pregnant women not using psychiatric medication selected from the database of the Netherlands Perinatal Registry foundation (Perined). Matching took place 1:5 for nine factors, i.e., parity, maternal age, ethnicity, socioeconomic status, macrosomia, gestational duration, history of postpartum haemorrhage, labour induction and hypertensive disorder.

Results: Postpartum haemorrhage occurred in $9.7 \%$ of the women using serotonergic medication. In the matched controls this was $6.6 \%(p=0.01)$. The adjusted odds ratio (aOR) before matching was $1.6(95 \% \mathrm{Cl} 1.2-2.1)$ and after matching 1.5 (95\% Cl 1.1-2.1). Among the women using other psychopharmacological medication, the incidence of postpartum haemorrhage before matching was $12.0 \%$ versus $6.1 \%(p=0.08)$ with OR $2.1(95 \% \mathrm{Cl} 0.9-4.9)$, and after matching $12.1 \%$ versus $4.4 \%(p=0.03)$ with aOR of $3.3(95 \% \mathrm{Cl} 1.1-9.8)$.

Conclusions: Pregnant women using serotonergic medication have an increased risk of postpartum haemorrhage, but this high risk is also seen in pregnant women using other psychopharmacological medication. We suggest that this higher risk of postpartum haemorrhage could not only be explained by serotonin, but also by other mechanisms. An additional explanation could be the underlying psychiatric disorder.

Keywords: Postpartum haemorrhage, Antidepressants, Serotonin, Postpartum blood loss, Pregnancy, Selective serotonin reuptake inhibitors, Psychopharmacological medication

\footnotetext{
*Correspondence: hm.heller@vumc.nl

'Department of Hospital Psychiatry, VU University Medical Centre, De

Boelelaan 1117, 1081 HV Amsterdam, The Netherlands

Full list of author information is available at the end of the article
} 


\section{Background}

Postpartum haemorrhage ( $\mathrm{PPH})$ is a major obstetric risk worldwide, with an increasing incidence in developed countries $[1,2]$. In the Netherlands the overall incidence of PPH defined as blood loss of more than $1000 \mathrm{ml}$ was around 6\% in 2014 [3]. Despite the growing knowledge about risk factors, we are still unable to fully explain the increasing incidence of this obstetric complication. Recent studies suggest that the use of serotonergic antidepressants in pregnancy might be associated with a higher risk of $\mathrm{PPH}[4-8]$.

Several studies have investigated the association of serotonergic antidepressant exposure during pregnancy and $\mathrm{PPH}$, with varying outcomes [4]. Some studies concluded that pregnant women using serotonergic antidepressants have an almost two times higher risk of PPH [5-9] whilst others reported no increased risk [10-13]. A recent systematic review and meta-analysis revealed that not only SSRI's, but also non serotonergic antidepressants are associated with a higher risk on PPH [14].

Treatment with antidepressants is often discontinued or not started or resumed during pregnancy because of possible foetal and obstetric complications [15]. On the other hand, untreated depression in pregnancy is associated with adverse neonatal outcome, such as an increased risk of prematurity, dysmaturity, decreased breastfeeding initiation [16, 17], increased risk of operative delivery [18-20], increased risk of caesarean delivery or rupture of the anal sphincter [21], increased risk of postpartum depression $[22,23]$ and affective and behavioural consequences for the offspring $[24,25]$. Some of these complications are associated with postpartum haemorrhage. Therefore, the use of antidepressants in pregnancy mostly outweighs its potential risks; its use is increasing in more highly developed countries [26-28]. This underscores the need to investigate the effectiveness and safety of treatment options for depression in pregnancy and postpartum.

The most frequently prescribed antidepressants, the serotonin reuptake inhibitors (SSRIs), are estimated to be used by 2 to $3 \%$ of the pregnant women in Europe and by $10 \%$ in North America [15]. A frequently proposed hypothesis for the aetiology of $\mathrm{PPH}$ in these women is that the use of serotonergic medication, more specifically the serotonergic action of these drugs on platelets, causes diminished blood clotting [29].

However, the varying incidence of $\mathrm{PPH}$ in these women may also relate to confounding due to the large number of other factors that contribute to this complication. It is therefore important to properly adjust for these confounding factors [4]. The first aim of our study was to investigate the role of serotonergic medication on the development of $\mathrm{PPH}$ reducing as much as possible the effect of potential confounders by performing a matched paired cohort analysis.
Our secondary aim was to determine the effect of other psychopharmacological medication, such as lithium and antipsychotics on the development of PPH. However, we didn't expect antipsychotics to increase PPH, because most studies show that the use of especially second generation antipsychotics leads to an increased risk of platelet aggregation. [30]. Some other psychopharmacological drugs are supposed to have also a kind of serotonergic action including contributing to the serotonin syndrome [31] but are not the affecting the blood clotting in the same way.

Based on previous studies, we hypothesized that the risk of $\mathrm{PPH}$ is higher for serotonergic drugs than for no drugs or for other psychopharmacological medication. This question about the contribution of serotonergic drugs to the development of $\mathrm{PPH}$ is of the utmost importance since use in pregnancy has increased and better knowledge of outcomes can help pregnant women and clinicians make more informed decisions concerning care.

\section{Methods}

\section{Setting, population and study participants}

We consecutively included all women in two hospitals, Sint Lucas Andreas Hospital and Onze Lieve Vrouwe Gasthuis, in Amsterdam, the Netherlands, between 2007 and 2014 who used psychopharmacological medication during pregnancy. In the Netherlands most pregnant women receive prenatal care from a midwife residing in or outside the hospital. Only women with (expected) complications during pregnancy or delivery are seen by a gynaecologist. Since taking psychotropic medication may cause for example withdrawal symptoms in the baby or postpartum haemorrhage in the mother this can be a (sole) reason for referral to a gynaecologist.

The data from their visits to the hospitals and their deliveries were extracted from the patient charts. The study was approved by the research and ethics board of both hospitals (registration number 14-096).

The cohort was defined as consisting of single pregnancies of women who used psychopharmacological medication in the third trimester. The first cohort group used serotonergic antidepressants (SSRIs, TCAs or SNRIs) with or without other psychopharmacological medication (cohort 1) and the second cohort group only used other psychopharmacological medication (antipsychotics, lithium) but no antidepressants, except for bupropion(cohort 2), all in the third trimester. Bupropion was classified in the non-serotonergic group since its action is related to the inhibition of dopamine and noradrenaline reuptake. All cohort members delivered from 32.0 weeks onwards. 


\section{Study design}

We conducted a matched cohort study consisting of either pregnancies of women taking serotonergic medication or pregnancies of women taking other psychopharmacological medication. We matched these women to pregnancies of women without documented psychiatric problems and measured the outcome $\mathrm{PPH}$, since data on the use of psychiatric medication in the control population were not available.

\section{Controls}

To identify matched controls, we used the linked national perinatal database of the Netherlands Perinatal Registry foundation (PRN or named PERINED since 2016; PERINED approvalnr. 15.34) The PERINED registry covers $96 \%$ of all deliveries in the Netherlands and contains anonymous information on pregnancies, deliveries $\geq$ 22 weeks of gestation and readmission of the child until 28 days after birth [32]. Because the definition of the PERINED database variables changed from 2010 onwards, we used the data set of the recent years 2010-2014.

Exclusion criteria for controls were documented psychiatric problems, delivery in either of the two hospitals or the primary care facility where the cohort members delivered, and women with a length of gestation of less than 32 weeks.

We matched for parity (nulliparity vs multiparity), maternal age ( $<35, \geq 35$ years), ethnicity (Caucasian, nonCaucasian), socioeconomic status (low, middle/high), macrosomia (birth weight above $90^{\text {th }}$ percentile adjusted for gestational age and parity), gestational duration $(\leq 37$ or $>37$ weeks), history of $\mathrm{PPH}$ (yes/no), induction of labour and hypertensive disorder (yes/no) to make the characteristics of the "type of woman" who used serotonergic or other medication comparable to the controls. We selected 5 controls for each cohort member and matched on equality or nearest neighbour.

In the Netherlands the socioeconomic status (SES) is determined by the Netherlands Institute for Social Research based on the 4-digit zip code, and the score is divided into low SES versus mid/high. The zip code is used nationwide to classify neighbourhoods for example as disadvantaged based om population density, educational level and percentage of low income [33]. The $90^{\text {th }}$ percentile is based on the Dutch reference curve for birthweight by gestational age, parity, ethnicity and gender [34].

The matching factors were based on the 2009 guidelines of the Royal College of Obstetricians and Gynaecologists (revised in 2011), identified factors in literature, clinical reasoning and availability in both databases.

\section{Primary outcome measurements}

Outcome was defined as $\mathrm{PPH}$ with postpartum blood loss exceeding $1000 \mathrm{ml}$.

\section{Statistical analysis}

At first, in the 'unmatched' cohort, we used traditional analysing techniques (i.e., crude and adjusted logistic regression) to control for confounders in the women who used serotonergic medication and compared them with the controls. Univariate analyses of the baseline characteristics were performed with a chi-square test for categorical variables. Next we matched on the nine factors and repeated the analysis. Maternal and pregnancy baseline characteristics of the women who used serotonergic antidepressants and all the controls were described.

Secondarily, we repeated the analysis, the matching and the analysis after matching for the patients who only used other (non-serotonergic) psychopharmacological medication and compared these with the controls. To estimate the influence of the serotonergic and other psychopharmacological medication on PPH, univariate and multivariate logistic regression analyses were performed both before and after matching. In the adjusted logistic regression analysis, the same nine matching variables were used, supplemented with year of birth of the child.

We could not match for intermediate variables in the causal path of postpartum haemorrhage. The intermediate factors were mode of delivery (operative vaginal delivery or delivery by emergency caesarean section), episiotomy, perineal laceration (defined as third- and fourth-degree tears "total rupture") and retained placenta. Therefore, in addition to the matching, we performed a stratified analysis only for the cohort using serotonergic medication due to the small numbers in the cohort of women using other psychopharmacological medication.

All statistical tests were two-sided, and a $p$ value of 0.05 was chosen as the threshold for statistical significance. Data were analysed using SAS software version 9.3 (SAS institute Inc., Cary, NC, USA). The matching was analysed with $\mathrm{R}$ statistical software version 3.2.0 ( $\mathrm{T}$ Foundation for Statistical computing, Vienna, Austria) using the Matchit package.

\section{Results}

In total, 628 singleton pregnancies in women using psychopharmacological medication during the third trimester of pregnancy were included. There were 578 pregnancies in cohort 1 (women who used serotonergic medication) and 50 pregnancies in cohort 2 (women who used other psychopharmacological drugs). Of cohort 2 group, 27 women used antipsychotics (haloperidol, quetiapine, olanzapine, clozapine or flupentixol), eight used a mood stabiliser (lithium or sodium valproate), five used antipsychotics and also a mood stabiliser, two used antipsychotics and also a benzodiazepine, three used only benzodiazepines, one used an antipsychotic and bupropion, and five used only bupropion. $86 \%$ of 
these used monotherapy only. There were 641,364 controls.

\section{Women with serotonergic medication (cohort 1 group)}

Women in cohort 1 were more likely to be older than 35 years and to have a low socioeconomic status (SES). They were less likely to have Caucasian ethnicity. This group also had a higher percentage of women with a previous pregnancy complicated by premature birth and/or PPH (Table 1). No differences were found between the two groups for parity, induction of labour, maternal hypertension and macrosomia in the index pregnancy.

Before matching, PPH was more frequent in cohort 1 than among the 641,364 controls $(9.7 \%$ versus $6.1 \%$, $p<0.0003)$. The adjusted odds ratio (aOR) was 1.6 (95\% CI 1.2-2.1) (Table 2).

After matching, cohort 1 was compared with 2890 controls and the differences in the baseline characteristics disappeared (all $p$-values were non-significant). In cohort 1 , the percentage of $\mathrm{PPH}$ was significantly higher than controls, $9.7 \%$ versus $6.6 \%(p=0.0086)$ (Table 1$)$. The aOR was also significantly increased to 1.5 (95\% CI 1.1-2.1) (Table 2).

\section{Women using other psychopharmacological medication (cohort 2 group)}

First, we compared cohort 2 with the 641,364 controls (Table 3).

Before matching, cohort 2 comprised more nulliparous women and more women with non-Caucasian ethnicity, low SES and increased maternal age than the control group. The percentage of PPH in cohort 2 did not differ significantly from the percentage in the controls $(12.0 \%$ versus $6.1 \%,(p=0.082)$. The adjusted odds ratio did not significantly increase: aOR $2.1 \quad(95 \%$ CI $0.9-4.9)$ (Table 4).

After matching, cohort 2 was comparable to 250 controls, and the incidence of PPH among the target population with other psychopharmacological drugs was significantly higher than among these comparable controls $(12.1 \%$ versus $4.4 \%(p=0.034)$. The adjusted odds ratio was significantly higher: $3.3(95 \%$ CI $1.1-9.8)$ (Tables 3 and 4).

\section{Stratified analyses}

We performed a stratified analysis for intermediate factors in cohort 1 with a PPH of 9.7\% and the 2890 controls with a PPH of $6.6 \%$. In cohort $1, \mathrm{PPH}$ was more common among women with operative vaginal deliveries $(15.7 \%$ versus $7.5 \% ; p=0.0083)$ than in controls with operative vaginal deliveries. $\mathrm{PPH}$ was also more common among women in cohort 1 who delivered via emergency caesarean delivery $(19.6 \%$ versus $5.7 \% ; p=0.0009)$.

However, in cohort 1, women with a perineal laceration had a lower incidence of PPH than controls with a perineal laceration $(3.8 \%$ versus $12.9 \%, p=0.0266)$. Among women with retained placentas, the risk of PPH was very high, but this risk was lower in women of cohort 1 compared to the controls $(36.7 \%$ versus $62.6 \%$; $p=0.0034)$.

\section{Discussion}

\section{Main findings}

In our study we tried to unravel the influence the role of serotonergic medication on the development of $\mathrm{PPH}$

Table 1 Baseline characteristics and the outcomes of the 578 women using serotonergic medication and the controls before and after matching

\begin{tabular}{|c|c|c|c|c|c|c|c|c|c|c|}
\hline & \multicolumn{5}{|c|}{ Before matching } & \multicolumn{5}{|c|}{ After matching with 5 controls } \\
\hline & \multicolumn{2}{|c|}{ Women with SRmed } & \multicolumn{3}{|c|}{ Controls (Perined) } & \multicolumn{3}{|c|}{ Women with SRmed } & \multicolumn{2}{|c|}{ Controls (Perined) } \\
\hline & $(n=578)$ & $\%$ & $(n=641,364)$ & $\%$ & $\overline{p \text {-value }}$ & $(n=578)$ & $\%$ & $(n=2890)$ & $\%$ & $p$-value \\
\hline \multicolumn{11}{|l|}{ Characteristics } \\
\hline Nulliparity & 258 & $44.6 \%$ & 289,190 & $45.1 \%$ & NS & 258 & $44.6 \%$ & 1290 & $44.6 \%$ & NS \\
\hline Caucasian ethnicity & 351 & $60.7 \%$ & 522,141 & $81.4 \%$ & $<0.0001$ & 351 & $60.7 \%$ & 1750 & $60.6 \%$ & NS \\
\hline Low socioeconomic status & 286 & $49.5 \%$ & 155,183 & $24.2 \%$ & $<0.0001$ & 286 & $49.5 \%$ & 1429 & $49.4 \%$ & NS \\
\hline Maternal age $>=35$ years & 195 & $33.7 \%$ & 131,584 & $20.5 \%$ & $<0.0001$ & 195 & $33.7 \%$ & 971 & $33.6 \%$ & NS \\
\hline Previous PPH & 16 & $2.8 \%$ & 6782 & $1.1 \%$ & $<0.0001$ & 16 & $2.8 \%$ & 80 & $2.8 \%$ & NS \\
\hline Induction of labour & 135 & $23.4 \%$ & 135,251 & $21.1 \%$ & NS & 135 & $23.4 \%$ & 674 & $23.3 \%$ & NS \\
\hline Hypertension & 47 & $8.1 \%$ & 52,763 & $8.2 \%$ & NS & 47 & $8.1 \%$ & 230 & $8.0 \%$ & NS \\
\hline Macrosomia P90 & 59 & $10.2 \%$ & 65,522 & $10.2 \%$ & NS & 59 & $10.2 \%$ & 290 & $10.0 \%$ & NS \\
\hline Gestational duration $<37$ weeks & 43 & $7.4 \%$ & 34,322 & $5.4 \%$ & 0.0258 & 43 & $7.4 \%$ & 216 & $7.5 \%$ & NS \\
\hline \multicolumn{11}{|l|}{ Outcome } \\
\hline PPH (>1000 ml) & 56 & $9.7 \%$ & 39,171 & $6.1 \%$ & 0.0003 & 56 & $9.7 \%$ & 191 & $6.6 \%$ & 0.009 \\
\hline
\end{tabular}

SRmed: serotonergic medication 
Table 2 Postpartum haemorrhage after use of serotonergic medication $(N=578)$ versus controls before and after matching

\begin{tabular}{|c|c|c|c|c|}
\hline & \multicolumn{2}{|c|}{ Crude Odds } & \multicolumn{2}{|c|}{ Adjusted Odds ${ }^{a}$} \\
\hline & \multicolumn{2}{|c|}{$95 \%$ C.I. } & \multicolumn{2}{|c|}{ 95\% C.I. } \\
\hline \multicolumn{5}{|l|}{ Outcome before matching } \\
\hline postpartum haemorrhage & 1.7 & $1.3-2.2$ & 1.6 & $1.2-2.1$ \\
\hline \multicolumn{5}{|l|}{ Outcome after matching } \\
\hline postpartum haemorrhage & 1.5 & $1.1-2.1$ & 1.5 & $1.1-2.1$ \\
\hline
\end{tabular}

${ }^{a}$ Adjusted for parity, maternal age, ethnicity, socio-economic status, previous postpartum haemorrhage, hypertension, macrosomia, induction of labour, year of birth and prematurity

reducing as much as possible the effect of potential confounders by performing a matched paired cohort analysis. Secondary we tried to investigate the influence of other psychopharmacological medication on the development of $\mathrm{PPH}$.

Our findings of a higher prevalence of PPH among women using serotonergic medication in the third trimester of pregnancy is in line with the hypothesis we based on previous studies.

On the other hand this prevalence was also increased in women using other psychopharmacological medication. In our population of women using medication with a serotonergic action, we found a 1.5-fold higher percentage of $\mathrm{PPH}$ than in a matched control population of women who did not take any psychopharmacological medication. In the group of women using other psychopharmacological medication, this percentage was almost 3 times larger than in the matched control population. In both groups of women using any psychopharmacological medication, the adjusted odds ratios of $\mathrm{PPH}$ were significantly higher than in the control group (1.5 resp. 3.3, Tables 2 and 4).

\section{Strengths and limitations}

Several strengths and limitations of our study design need to be addressed. The first strength is that we compared the incidence of PPH both in women using serotonergic antidepressants and in women using other psychopharmacological medication to the incidence in women not using any psychopharmacological medication. Secondly, by using a match cohort study we have matched our study population for nine possible confounding variables. In this way we could, despite our small study population, minimize the influence of wellestablished maternal and pregnancy confounders. Having 5 controls instead of 3 or 1 per participant increased the sample size [35]. A match cohort study can minimize observed measured differences in characteristics among the participants and the controls.

However they cannot rule out unmeasured and unknown factors. Therefore, a limitation is that we had to leave out two well established matching variables, BMI and smoking, since these variables unfortunately were not available in the national PERINED databases. However, the incidence of obesity and smoking in our population was low, $5 \%$ of the pregnant women smoked more than 1 cigarette a day and 1,5\% smoked more than 10 cigarettes a day. Obesity, defined as BMI above $30 \mathrm{~kg} / \mathrm{m}^{2}$ occurred in $3.3 \%$ of our study population. These data suggest that these confounders probably did not have a considerable influence on our results.

A second limitation is that in the serotonergic cohort some of the matched factors could be also considered as intermediate factors, like hypertensive disorders in pregnancy, foetal growth retardation and preterm birth. Therefore we repeated the matching with only five

Table 3 Baseline characteristics and the outcomes of the 50 women using other psychopharmacological medication and the controls before and after matching

\begin{tabular}{|c|c|c|c|c|c|c|c|c|c|c|}
\hline & \multicolumn{5}{|c|}{ Before matching } & \multicolumn{5}{|c|}{ After matching with 5 controls } \\
\hline & \multicolumn{2}{|c|}{ other ps.drugs } & \multicolumn{3}{|c|}{ Controls (Perined) } & \multicolumn{2}{|c|}{ other ps.drugs } & \multicolumn{3}{|c|}{ Controls (Perined) } \\
\hline & $(n=50)$ & $\%$ & $(n=641,364)$ & $\%$ & $p$-value & $n=50$ & $\%$ & $n=250$ & $\%$ & $p$-value \\
\hline \multicolumn{11}{|l|}{ Characteristics } \\
\hline Nulliparity & 29 & $58.0 \%$ & 289,190 & $45.1 \%$ & 0.0666 & 29 & $58.0 \%$ & 145 & $58.0 \%$ & NS \\
\hline Caucasian ethnicity & 26 & $52.0 \%$ & 522,141 & $81.4 \%$ & $<0.0001$ & 26 & $52.0 \%$ & 130 & $52.0 \%$ & NS \\
\hline Low socioeconomic status & 23 & $46.0 \%$ & 155,183 & $24.2 \%$ & 0.0003 & 23 & $46.0 \%$ & 115 & $46.0 \%$ & NS \\
\hline Maternal age $>=35$ years & 16 & $32.0 \%$ & 131,584 & $20.5 \%$ & 0.044 & 16 & $32.0 \%$ & 80 & $32.0 \%$ & NS \\
\hline Previous PPH & 0 & $0.0 \%$ & 6782 & $1.1 \%$ & NS & 0 & $0.0 \%$ & 0 & $0.0 \%$ & NS \\
\hline Induction of labour & 15 & $30.0 \%$ & 135,251 & $21.1 \%$ & NS & 15 & $30.0 \%$ & 75 & $30.0 \%$ & NS \\
\hline Hypertension & 4 & $8.0 \%$ & 52,763 & $8.2 \%$ & NS & 4 & $8.0 \%$ & 20 & $8.0 \%$ & NS \\
\hline Macrosomia P90 & 6 & $12.0 \%$ & 65,522 & $10.2 \%$ & NS & 6 & $12.0 \%$ & 30 & $12.0 \%$ & NS \\
\hline Gestational duration $<37$ weeks & 5 & $10.0 \%$ & 34,322 & $5.4 \%$ & NS & 5 & $10.0 \%$ & 25 & $10.0 \%$ & NS \\
\hline \multicolumn{11}{|l|}{ Outcome } \\
\hline PPH (>1000 ml) & 6 & $12.0 \%$ & 39,171 & $6.1 \%$ & 0.0819 & 6 & $12.0 \%$ & 11 & $4.4 \%$ & 0.0339 \\
\hline
\end{tabular}

ps.drugs: other psycofarmacological drugs 
Table 4 Postpartum haemorrhage after use of other psychopharmacological drugs $(n=50)$ before and after matching

\begin{tabular}{|c|c|c|c|c|}
\hline & \multicolumn{2}{|c|}{ Crude Odds } & \multicolumn{2}{|c|}{ Adjusted Odds ${ }^{a}$} \\
\hline & \multicolumn{2}{|c|}{ 95\% C.I. } & \multicolumn{2}{|c|}{ 95\% C.I. } \\
\hline \multicolumn{5}{|l|}{ Outcome before matching } \\
\hline Postpartum haemorrhage & 2.1 & $0.9-4.9$ & 2.1 & $0.9-4.9$ \\
\hline \multicolumn{5}{|l|}{ Outcome after matching } \\
\hline Postpartum haemorrhage & 3.0 & $1.0-8.4$ & 3.3 & $1.1-9.8$ \\
\hline
\end{tabular}

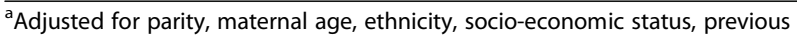
postpartum haemorrhage, hypertension, macrosomia, induction of labour, year of birth and prematurity

factors and performed a conditional analysis for this group. The adjusted odds ratio of the women using serotoninergic drugs was 1.7 (CI 1.2-1.3) which is even higher than in the first matching and analysis. We performed the matching with five factors and conditional analysis in the other psychopharmacological cohort $(n=50)$, and the risk was also increased ( $12 \%$ versus 6\%) but no longer significant i.e., 1.9 (CI 0.7-5.4). This can be explained through the fact that the numbers of PPH cases are small in this cohort. Another explanation could be that the previous mentioned intermediate factors in the serotonergic cohort are not in the same way applicable to the cohort of women using other psychopharmacological medication [36-38].

A third limitation is that the PERINED database does not have information on the actual medication of women during pregnancy nor on depression during pregnancy. Nevertheless, we excluded all women with records of psychological problems or diseases in the PERINED database, but we cannot completely rule out that some women among the controls may also have used serotonergic or other psychopharmacological medication. On the other hand, this limitation only means that we may have underestimated the effects found in this study. A third limitation is that cohort 2 was relatively small, which made it difficult to perform a stratified analysis in this group.

\section{Interpretation}

Our finding that the use of serotoninergic drugs increases the risk of $\mathrm{PPH}$ is in agreement with at least five previous studies [5-9]. Some of these studies compared the risk of $\mathrm{PPH}$ between women using the medication in different stages of pregnancy [9], and other studies examined women with a psychiatric illness without medication [5]. These approaches do not take into account the potential role of the severity of the underlying psychiatric disorder, since taking women with psychiatric complaints but not using medication as controls probably implies leaving out the more severely ill. Also in those investigations, the severity of psychiatric disorders rather than medication use could be the risk factor related to $\mathrm{PPH}$, since women with stress due to psychiatric problems may be more prone to prolonged labour [21, 39]. Prolonged labour in itself constitutes a risk factor for PPH [40], but also for delivery by emergency caesarean section and for operative vaginal delivery $[18,19]$, and both types of delivery also contribute to the development of PPH.

A second explanation for other psychopharmacological medication generating a higher incidence of $\mathrm{PPH}$ could be that even though this medication does not directly influence serotoninergic action, it might affect other neurotransmitters and thus create a shift in the neurotransmitter balance, which may indirectly affect the platelet function.

\section{Conclusion}

Our study sheds a new light on the possible influence of psychopharmacological medication on postpartum haemorrhage. The hypothesis that the serotonergic action of antidepressant medication plays a main role in the development of PPH probably does not constitute the complete explanation. The results of our study suggest that serotonergic medication but also other psychopharmacological medication during pregnancy can result in a higher risk of PPH. However, it could be plausible that the acting mechanism is not only the medication, but also the underlying disease.

Future research should focus on blood loss postpartum in women using all types of psychopharmacological medication compared to women with equally serious psychiatric illness who do not use any of this medication during pregnancy.

\section{Abbreviations}

PPH: Postpartum haemorrhage; SES: Social economic status; BMI: Body mass index; PERINED: Netherlands perinatal registry foundation; SSRIs: Selective serotonin reuptake inhibitors; TCAs: Tricyclic antidepressants; SNRIs: Serotonin and noradrenalin reuptake inhibitors; aOR: Adjusted odds ratio

\section{Acknowledgements}

We thank Ms Nancy van der Mark and Ms Ine van der Spek for their contribution to the data collection.

Funding

This research study received no specific funding.

\section{Availability of data and materials}

The datasets of the cases used and/or analysed during the current study are available from the corresponding author on reasonable request. Request of the data set of the control population can be made to the Netherlands Perinatal Registry foundation (https://www. perined.nl/.

\section{Authors' contributions}

The authors were involved as follows: $H H, A R, A B, F S$ and $A H$, made substantial contributions to conception and design; $\mathrm{HH}, \mathrm{AH}, \mathrm{CdG}, \mathrm{MP}, \mathrm{AR}$ and FS participated in data acquisition; $H H, A R$, FS and $A H$ performed the analysis and interpretation of data; $H H, A B, A R, C d G, M P, F S$ and $A H$ have been involved in drafting the manuscript and revising it critically for important intellectual content; $\mathrm{HH}, \mathrm{AB}, \mathrm{AR}, \mathrm{CdG}, \mathrm{MP}, \mathrm{FS}$ and $\mathrm{AH}$ have given final approval of the version to be published. Each author has agreed to be accountable for all aspects of the work in ensuring that questions related to the accuracy or integrity of any part of the work are appropriately investigated and resolved. 


\section{Competing interests}

All authors have completed the Unified Competing Interest form available on request from the corresponding author and declare the following: no author received financial support for the submitted work; no financial relationships with any organizations that might have an interest in the submitted work in the previous 3 years; no other relationships or activities that hat could appear to have influenced the submitted work.

\section{Consent for publication \\ Not Applicable.}

\section{Ethics approval and consent to participate}

The advisory board of the scientific board of the OLVG approved the study (registration number 14-096). In 2015, when the research was carried out, the Onze Lieve Vrouwe Gasthuis and the Sint Lucas Andreas Hospital were already legally and administratively merged in one hospital named OLVG. The board of directors decided that from then on approval of the ethic committee of one hospital ensured approval at the other side. Informed consent of participants was not obtained since, in the Netherlands administrative permission in order to access patient information from patient charts is not needed if the information used is not personally identifiable, the study is retrospective, concerns large numbers of participants and it is not feasible to trace and contact individual participants. Perined (the Netherlands Perinatal Registry foundation) approved to use the data of the control population (registration number 15.34).

\section{Publisher's Note}

Springer Nature remains neutral with regard to jurisdictional claims in published maps and institutional affiliations.

\section{Author details \\ ${ }^{1}$ Department of Hospital Psychiatry, VU University Medical Centre, De Boelelaan 1117, 1081 HV Amsterdam, The Netherlands. ${ }^{2}$ Department of Medical Informatics, Academic Medical Centre, University of Amsterdam, Meibergdreef 9, 1105 AZ Amsterdam, The Netherlands. 'Department of Pediatric Infectious Diseases, Emma Children's Hospital, Academic Medical Centre, University of Amsterdam, Meibergdreef 9, 1105 AZ Amsterdam, The Netherlands. ${ }^{4}$ Department of Obstetrics and Gynaecology, VU University Medical Centre, De Boelelaan 1117, 1081 HV Amsterdam, The Netherlands. ${ }^{5}$ Department of Obstetrics and Gynaecology, OLVG Hospital (West), Jan Tooropstraat 164, 1061 AE Amsterdam, The Netherlands. 'Department of Obstetrics and Gynaecology, VU University Medical Centre, De Boelelaan 1117, 1081 HV Amsterdam, The Netherlands. ${ }^{7}$ Department of Obstetrics and Gynaecology, OLVG Hospital (East), Oosterpark 9, 1091 AC Amsterdam, The Netherlands. ${ }^{8}$ Department of Hospital Psychiatry, OLVG Hospital (West), Jan Tooropstraat 164, 1061 AE Amsterdam, The Netherlands. ${ }^{9}$ Department of Hospital Psychiatry, VU University Medical Centre, De Boelelaan 1117, 1081 HV Amsterdam, The Netherlands.}

\section{Received: 15 November 2016 Accepted: 18 May 2017}

\section{Published online: 02 June 2017}

\section{References}

1. Briley A, Seed PT, Tydeman G, Ballard H, Waterstone M, Sandall J, Poston L, Tribe RM, Bewleya S. Reporting errors, incidence and risk factors for postpartum haemorrhage and progression to severe $\mathrm{PPH}$ : a prospective observational study. BJOG. 2014;121:876-88.

2. Knight M, Callaghan WM, Berg C, Alexander S, Bouvier-Colle M-H, Ford JB, Joseph $\mathrm{K}$, Lewis $\mathrm{G}$, Liston RM, Roberts $\mathrm{CL}$, et al. Trends in postpartum hemorrhage in high resource countries: a review and recommendations from the International Postpartum Hemorrhage Collaborative Group. BMC Pregnancy Childbirth. 2009;9:55-65

3. Smit M, Chan K, Middeldorp J, van Roosmalen J. Postpartum haemorrhage in midwifery care in the Netherlands: validation of quality indicators for midwifery guidelines. BMC Pregnancy Childbirth. 2014;14:397-402.

4. Bruning AHL, Heller HM, Kieviet N, Bakker PCAM, de Groot CJM, Dolman KM, Honig A. Antidepressants during pregnancy and postpartum hemorrhage: a systematic review. Eur J Obstet Gynecol Reprod Biol. 2015;189:38-47.

5. Grzeskowiak LE, McBain R, Dekker GA, Clifton VL. Antidepressant use in late gestation and risk of postpartum haemorrhage: a retrospective cohort study. BJOG. 2016;123:1929-36.
6. Hanley GE, Smolina K, Mintzes B, Oberlander TF, Morgan SG. Postpartum hemorrhage and use of serotonin reuptake inhibitor antidepressants in pregnancy. Obstet Gynecol. 2016;127(3):553-61.

7. Joseph KS, Sheehy O, Mehrabadi A, Urquia ML, Hutcheon JA, Kramer M, Bérard A. Can drug effects explain the recent temporal increase in atonic postpartum haemorrhage? Paediatr Perinat Epidemiol. 2015;29:220-31.

8. Lindquist PG, Nasiell J, Gustafsson LL, Nordstrom L. Selective serotonin reuptake inhibitor use during pregnancy increases the risk of postpartum hemorrhage and anemia: a hospital-based cohort study. J Thromb Haemost. 2014;12(12):1986-92.

9. Palmsten K, Hernandez-Diaz S, Huybrechts KF, Williams PL, Michels KB, Achtyes ED, Mogun H, Setoguchi S. Use of antidepressants near delivery and risk of postpartum hemorrhage: cohort study of low income women in the United States. BMJ. 2013;347. doi:10.1136/bmj.f4877.

10. Kim DR, Pinheiro E, Luther JF, Eng HF, Dills JL, Wisniewski SR, Wisner KL. Is third trimester serotonin reuptake inhibitor use associated with postpartum hemorrhage? J Psychiatr Res. 2016;73:79-85.

11. Lupattelli A, Spigset $O$, Koren G, Nordeng H. Risk of vaginal bleeding and postpartum hemorrhage after use of antidepressants in pregnancy a study from the norwegian mother and child cohort study. J Clin Psychopharmacol. 2014;34(1):143-8.

12. Reis $M$, Källén $B$. Delivery outcome after maternal use of antidepressant drugs in pregnancy: an update using Swedish data. Psychol Med. 2010; 40(10):1723-33.

13. Salkeld E, Ferris LE, Juurlink DN. The risk of postpartum hemorrhage with selective serotonin reuptake inhibitors and other antidepressants. J Clin Psychopharmacol. 2008;28(2):230-4.

14. Jiang H, Xu L, Li Y, Deng M, Peng C, Ruan B. Antidepressant use during pregnancy and risk of postpartum hemorrhage: a systematic review and meta-analysis. J Psychiatr Res. 2016;83:160-7.

15. Zoega H, Kieler H, Nørgaard M, Furu K, Valdimarsdottir U, Brandt L, Haglund B. Use of SSRI and SNRI antidepressants during pregnancy: a populationbased study from Denmark, Iceland, Norway and Sweden. PLoS One. 2015; 10(12). doi:10.1371/journal.pone.0144474.

16. Grigoriadis $S$, VonderPorten $E H$, Mamisashvili $L$, Tomlinson $G$, Dennis $C L$, Koren G, Steiner M, Mousmanis P, Cheung A, Radford K, et al. The impact of maternal depression during pregnancy on perinatal outcomes: a systematic review and meta-analysis. J Clin Psychiatry. 2013;74(4):321-41.

17. Grote NK, Bridge JA, Gavin AR, Melville JL, lyengar S, Katon WJ. A meta-analysis of depression during pregnancy and the risk of preterm birth, low birth weight and intrauterine growth restriction. Arch Gen Psychiatry. 2010;67(10):1012-24.

18. Hu R, Li Y, Zhang Z, Yan W. Antenatal depressive symptoms and the risk of preeclampsia or operative deliveries: a meta-analysis. PLoS One. 2015;10(3). doi:10.1371/journal.pone.0119018.

19. Chung TKH, Lau TK, Yip ASK, Chiu HFK, Lee DTS. Antepartum depressive symptomatology is associated with adverse obstetric and neonatal outcomes. Psychosom Med. 2001:63:830-4.

20. Kinney DK, Yurgelun-Todd DA, Levy DL, Medoff D, Lajonchere CM, RadfordParegol M. Obstetrical complications in patients with bipolar disorder and their siblings. Psychiatry Res. 1993;48(1):47-56.

21. Andersson L, Sundstrom-Poromaa I, Wulff M, Åstrom M, Bixo M. Implications of antenatal depression and anxiety for obstetric outcome. Obstet Gynecol. 2004:104(3):467-76.

22. Dennis $\mathrm{CL}$, Dowswell T. Interventions (other than pharmacological, psychosocial or psychological) for treating antenatal depression (Review). Cochrane Database Syst Rev. 2013;31(7). doi:10.1002/14651858.CD006795. pub3.

23. Biaggi A, Conroy S, Pawlby S, Pariante CM. Identifying the women at risk of antenatal anxiety and depression: a systematicreview. J Affect Disord. 2016; 191:62-77.

24. Murray L, Sinclair D, Cooper P, Ducournau P, Turner P, Stein A. The socioemotional development of 5-year-old children of postnatally depressed mothers. J Child Psychol Psychiatry. 1999;40(8):1259-71.

25. Verbeek T, Bockting CLH, Pampus MG, Ormel J, Meijer JL, Hartman CA, Burger $\mathrm{H}$. Postpartum depression predicts offspring mental health problems in adolescence independently of parental lifetime psychopathology. J Affect Disord. 2012;136(3):948-54.

26. Cooper WO, Willy ME, Pont SJ, Ray WA. Increasing use of antidepressants in pregnancy. Am J Obstet Gynecol. 2007;196(6):544.e541-545.

27. Jimenez-Solem E. Exposure to antidepressants during pregnancyprevalences and outcomes. Dan Med J. 2014;61(9):B4916. 
28. Andrade SE, Raebel MA, Brown J, Lane K, Livingston J, Boudreau D, Rolnick SJ, Roblin D, Smith DH, Willy ME, et al. Use of antidepressant medications during pregnancy: a multisite study. Am J Obstet Gynecol. 2008;198:194.e191-5.

29. Andrade C, Sandarsh S, Chethan KB, Nagesh KS. Serotonin reuptake inhibitor antidepressants and abnormal bleeding: a review for clinicians and a reconsideration of mechanisms. J Clin Psychiatry. 2010;71(12):1565-75.

30. Dietrich-Muszalska A, Wachowicz B. Platelet haemostatic function in psychiatric disorders: effects of antidepressants and antipsychotic drugs. World J Biol Psychiatry. 2016;11(2-2):293-299.

31. Boyer EW, Shannin M. The serotonin syndrome. N Engl J Med. 2005;352(11): 1112-20.

32. Méray N, Reitsma JB, Ravelli AC, Bonsel GJ. Probabilistic record linkage is a valid and transparent tool to combine databases without a patient identification number. J Clin Epidemiol. 2007;60:883-91.

33. Devillé W, Wiegers TA. Recalibration deprived urban areas NIVEL 2012. 2015.

34. Visser GH, Eilers PH, Elferink-Stinkens PM, Merkus HM, Wit JM. New Dutch reference curves for birthweight by gestational age. Early Hum Dev. 2009; 85(12):737-44.

35. Rosenbaum P. Impact of multiple matched controls on design sensitivity in observational studies. Biometrics. 2013;69:118-27.

36. Vigod SN, Gomes T, Wilton AS, Taylor VH, Ray JG. Antipsychotic drug use in pregnancy: high dimensional, propensity matched, population based cohort study. BMJ. 2015;350:10. doi:10.1136/bmj.h2298.

37. Boden R, Lundgren M, Brandt L, Reutfors J, Andersen M, Kieler H. Risks of adverse pregnancy and birth outcomes in women treated or not treated with mood stabilisers for bipolar disorder: population based cohort study. BMJ. 2012;345. doi:10.1136/bmj.e7085.

38. Reis M, Kallen B. Maternal use of antipsychotics in early pregnancy and delivery outcome. J Clin Psychopharmacol. 2008;28:10.

39. Gisladottir A, Luque-Fernandez MA, Harlow BL, Gudmundsdottir $B$, Jonsdottir E, Bjarnadottir Rl, Hauksdottir A, Aspelund T, Cnattingius S, Valdimarsdottir UA. Obstetric outcomes of mothers previously exposed to sexual violence. PLOS ONE. 2015;11(3). doi:10.1371/journal.pone.0150726.

40. Royal College of Obstetricians and Gynaecologists: Postpartum Haemorrhage, Prevention and Management (Green-top Guideline No. 52) https://www.rcog.org.uk/en/guidelines-research-services/guidelines/gtg52/.

\section{Submit your next manuscript to BioMed Central and we will help you at every step:}

- We accept pre-submission inquiries

- Our selector tool helps you to find the most relevant journal

- We provide round the clock customer support

- Convenient online submission

- Thorough peer review

- Inclusion in PubMed and all major indexing services

- Maximum visibility for your research

Submit your manuscript at www.biomedcentral.com/submit 